\title{
The Language Protection Project Should Achieve Three "Unifications" Under the Background of Industrial Industrialization
}

\author{
ChangmingShen \\ School of Liberal Arts, Huangshan University, Huangshan, Anhui, China
}

\begin{abstract}
The Chinese Language Resources Protection Project (referred to as the "Language Protection Project") started in 2015 and has basically completed its original tasks so far. Combining the actual experience of participating in the language protection project and integrating the research results of others, And in the context of accelerating industrial industrialization and urbanization, the language protection project must achieve the best results, at least the top-level design, academic rationality and ideological unity; the unity of inheritance and innovation in the project implementation process; the unity of academic rigor and corpus value in project acceptance.
\end{abstract}

Keywords:Industrialization, Language preservation project, ideological, innovative, value of the times, unity

\section{Introduction}

In 2015, the Ministry of Education and the National Language Commission conducted a survey of about 500 Chinese dialects (including endangered dialects) and 400 minority languages (including endangered Language) points and 100 language and cultural points[1], through field surveys, online collection and document collection, etc. to realize the investigation and aggregation of Chinese language resources, construction and preservation, protection research, development and application projects [2], namely Chinese language resources The protection project, referred to as the language protection project (the language protection project referred to in this article, specifically refers to the investigation of Chinese dialects). The language preservation project has attracted widespread attention from the society because of its wide coverage, large number of participants, and fruitful results. Some scholars have pointed out that the language preservation project has academic defects such as lack of comprehensive content and insufficient quantity sufficiency [3]. In fact, the biggest shortcoming is that the entire project pays too much attention to academics and ignores ideological properties, that is, lacks guiding ideology. "It is necessary to dig and interpret the values of the times of benevolence, people-oriented, honesty, justice, harmony, and unity in the excellent traditional Chinese culture, and make it an important source of the core values of socialism." [4] The sentence highly summarizes the value of the times of the excellent Chinese traditional culture, clarifies the origin between the excellent Chinese traditional culture and the core socialist values, and also provides ideological guidance for the practice of the language preservation project that is being implemented. Therefore, the language protection project should achieve the unity of academic rationality and ideology in the top-level design, and promote the promotion of Chinese excellent traditional culture as its own responsibility; in the implementation of the project, it should achieve the unity of inheritance and innovation, and in-depth exploration of the excellent Chinese traditional culture. The value of the times; the academic rigor and the value of the times should be unified in the acceptance of the project, and the language protection project should be made into a high-quality product.

II.The top-level design of the language preservation project achieves the unity of academic rationality and ideology

As we all know, our country has a vast territory and Chinese dialects are very complicated. There has always been a saying that "five li has different sounds and ten li has different vulgar". Chinese dialect is also a carrier of regional culture and an important living language resource. After thousands of years of development and evolution, its content is mixed, various ideologies are intertwined, elegance and vulgarity coexist, essence and dregs coexist, and the face is so complicated. In a complicated situation, it is easy to get lost and go astray without thinking. Therefore,

ISSN: 0010-8189 
the language protection project designer who takes the protection, inheritance, display, development, and utilization of Chinese language resources as its own responsibility must first clarify the guiding ideology of the language protection project, that is, clearly define what to protect, inherit, display, develop and use. The traditional language and culture are all inclusive and should be selected. The "Manual for the Survey of Chinese Dialects" should not only involve technical specifications, but also clarify the guiding ideology of the language protection project, fully reflect the ideological requirements, and master the leadership and discourse power of ideological work. Ideological work is an extremely important work. It is a work to build a heart for the country and a soul for the nation. To do a good job in ideological work, we must uphold and strengthen the overall leadership of ideological work, and firmly grasp the leadership of ideological work. We must pay attention to all-round penetration and deep integration, and work hard in detail, small, and implementation. [5] The Language Protection Project should examine and deal with this issue from the perspective of socialist ideological leadership.

Therefore, the language protection engineering design must adhere to the academic rationality and the ideological nature, and it must be upright and innovative. The so-called "shouzheng" is to design language resource survey items and specific items in accordance with the general laws of language resource protection work in academic theory to meet the actual needs of the language protection project. The so-called "innovation" means to examine and standardize item design from the perspective of socialist ideological leadership, especially to review vocabulary items, discourse topics, oral culture and other designs in detail, and discard those that do not conform to mainstream consciousness or Items that do not have contemporary value, such as: "0497 verbs" in vocabulary items, "0503 is equivalent to a' fuck' mantra", and "swear words" in optional items of oral culture; Innovate the content design of discourse topics and oral culture to achieve compatibility between tradition and reality. It is necessary to retain traditional items in the excellent traditional language and culture that conform to the mainstream consciousness, and to increase survey items reflecting the current great practice of socialist construction with Chinese characteristics. Resonate at the same frequency with the new era. The Chinese leader once pointed out, "The core values of a nation and a country must be compatible with the history and culture of this nation and this country, combined with the ongoing struggles of this nation and the people of this country, and be consistent with the needs of this nation and this country. Adapt to the solved problems of the times." [6]. Based on this, we can reflect the current political, economic, cultural, ecological, and clean government construction terms involved in the current construction of socialism with Chinese characteristics that are in full swing in the design of the vocabulary survey project. Topics such as new rural construction, garbage classification and environmental protection, precision poverty alleviation, and clean government culture can be added to the discourse survey. In the survey of oral culture, contemporary nursery rhymes, stories, chanting, etc. reflecting the new era, new atmosphere, and new deeds are added.

\section{To achieve the unity of inheritance and innovation in project implementation}

With the development of my country's society and economy, the acceleration of urbanization and the increasing frequency of population movements, the ecology on which traditional language and culture depend for survival and inheritance has undergone tremendous changes, and some have even disappeared. Those who are familiar with the traditional oral language and culture are generally the elderly, and the way of inheritance is mostly oral. It can be said that they are the "porters" of the oral language and culture. For their traditional language and culture, they lack aesthetic value judgments that are higher than the concept of right and wrong. As the implementers of the language protection project, they must use the core socialist values as their ideological guidance, and carry out creative transformation and innovative development of the provided corpus. Creative transformation means to transform those connotations and outdated expressions that still have reference value in accordance with the characteristics and requirements of the times, give them new connotations of the times and modern expressions, and activate their vitality. Innovative development means to supplement, expand, and improve the connotation of Chinese excellent traditional culture in accordance with the new progress and progress of the times, and to increase its influence and appeal. [6] Therefore, on the one hand, we must encourage speakers to boldly sing the new era in traditional cultural styles, praise the new life, and give new connotations to the excellent traditional Chinese culture.

Guide speakers to make full use of the artistic expressions of traditional oral culture, such as nursery rhymes, folk

ISSN: 0010-8189 
songs, jingle, allegro, local dramas and other existing melodies and rhymes, and reflect current real life under the guidance of core values. On the other hand, as the implementer of the language protection project, we must dig deeper and extract language materials that are rich in the value of the times, such as "speaking of benevolence, emphasizing the people, keeping integrity, advocating justice, advocating harmony, and seeking great unity" in traditional oral culture. , Resolutely abandon those corpus with feudal superstition, extreme selfishness and selfishness, and all vulgar, vulgar and kitsch corpus, in order to ensure the purity and health of the corpus, and consciously assume the mission of raising the banner, gathering people's hearts, cultivating newcomers, developing culture, and exhibiting images The mission is to tell the story of China well and spread the voice of China well.

\section{Achieve the unification of academic rigor and material value orientation in engineering acceptance}

We must clearly express our attitude towards various bad literary works, phenomena, and trends of thought, and express our position on major issues of right and wrong. [7] The acceptance of the language protection project should advocate a new trend of stressing politics, taste, style, and responsibility, consciously resist vulgarity, vulgarity, and kitsch, and put the language material in a prominent position whether it conforms to the core values and whether it has the value of the times. Project acceptance check. Resolutely put an end to the use of the language preservation project as a banner to promote feudal and superstition thoughts that are inconsistent with mainstream ideologies and values of the times. On this basis, the academic dialect phonetics description, annotation review, and technical level audio and video recording quality review are carried out, so as to complete the mission and tasks assigned by the language protection project.

\section{Conclusion}

The language resources protection project is a national project. It must have the atmosphere of a big country and the demeanor of a big country. It must be guided by the socialist ideology of the new era with Chinese characteristics to protect the practice of the language project. The engineering design must be unified with academic rationality and ideology, and promote and inherit the excellent Chinese language. Culture; in the implementation of the project, the inheritance and innovation are unified, and the value of the traditional culture is fully explored; in the acceptance of the project, the academic rigor and the value of the corpus are unified, and the core value concept is advocated. Only in this way can the spiritual connotations of excellent traditional language and culture be refined and displayed, and used as the core of language resource protection, enhance the charm of Chinese language, and truly realize "remember homesickness and retain the local accent."

\section{Acknowledgements}

This research was supported by An Investigation of Chinese Dialects in Anhui Huizhou (YB1901A004).

\section{References}

[1] L. X. Tian, "The origin and significance of the Chinese Language Resources Protection Project". Application of Language and Writing, 2015(04), 2-9.

[2] Z. Y. Cao, "The positioning, goals and tasks of the Chinese Language Resources Protection Project". Application of Language and Writing, 2015(04), 10-17.

[3] J. J. Fan, "The use of corpus resources in the language preservation project". Journal of Northwest University for Nationalities (Philosophy and Social Sciences Edition), 2019(03), 18-23.

[4] The Propaganda Department of the Central Committee of the Communist Party of China. Xi Jinping's New Era Socialism Thought with Chinese Characteristics Study Outline. Beijing: Learning Publishing House. People's Publishing House. 2019.6, 147-147

[5] The Propaganda Department of the Central Committee of the Communist Party of China. Xi Jinping's New Era Socialist Thought with Chinese Characteristics Study Outline. Beijing: Learning Publishing House. People's Publishing House. 2019.6, 140-140

ISSN: 0010-8189 
[6] The Propaganda Department of the Central Committee of the Communist Party of China. Xi Jinping's New Era Socialism Thought with Chinese Characteristics Study Outline. Beijing: Learning Publishing House. People's Publishing House. 2019.6, 145-145

[7] The Propaganda Department of the Central Committee of the Communist Party of China. Xi Jinping's New Era Learning Outline of Socialism with Chinese Characteristics. Beijing: Learning Publishing House. People's Publishing House. 2019.6, 150-150 